\title{
"Effect of Mind Sound Resonance Technique (A Yogic Relaxation Technique) on Cognitive Functions in Elderly Population"
}

\author{
Dr. Vijaya Kumar $\mathrm{PS}^{1 *}$, Sahana $\mathrm{AU}^{2}$, Vaidehi Rangarajan ${ }^{3}$
}

${ }^{1}$ Associate Professor BAMS, MD (Yoga \& rehab.), Msc (psy), ${ }^{2}$ Clinical psychologists Msc (Clinical psychology), ${ }^{3}$ PG Scholar Msc (Yoga), S-VYASA
University \#19, Ekanath bhavan, gavipuram circle, kempegowda nagar Bangalore - 560019, India

DOI: $10.36348 /$ sijtcm.2020.v03i07.003

| Received: 06.07.2020 | Accepted: 13.07.2020 | Published: 16.07.2020

*Corresponding author: Dr. Vijaya Kumar PS

\section{Abstract}

Background: Aging is a normal process in the life of all living beings. It is a multidimensional process of physical, psychological, and social change. Some dimensions of ageing grow and expand over time, while others decline. The study looks at effect of MSRT a yoga technique in elderly to improve cognitive functions like attention, concentration, short term memory and executive functions. Materials and Methods: Elderly subjects were recruited based on inclusion and exclusion criteria $(\mathrm{n}=30)$ for a single group interventional pre-post study design: MSRT (a relaxation technique) was given for a period of 1 month (30 days). The subjects were assessed on day 1 pre and post intervention on day 30 on Six Letter Cancellation Test (SLCT), and Trail Making Test-B (TMT-B). Results: After one month of MSRT practice showed significantly better performance in the SLCT test compared to baseline by Paired sample t test $(\mathrm{P}<0.0001)$ and TMT-B scores $(\mathrm{P}<0.0001)$. Conclusions: The results of this study establish that MSRT can be used as a technique to enhance cognition and prevent cognitive decline in the elderly.

Keywords: MSRT: Mind sound resonance technique, Cognitive decline, Elderly.

Copyright @ 2020: This is an open-access article distributed under the terms of the Creative Commons Attribution license which permits unrestricted use, distribution, and reproduction in any medium for non-commercial use (NonCommercial, or CC-BY-NC) provided the original author and source are credited.

\section{INTRODUCTION}

Aging is a normal process in the life of all living beings. It is an intricate process of physical, psychological, and social change. The basic cognitive functions most affected by age are attention and memory, neither of these are unitary functions, however, evidence suggests that some aspects of attention and memory hold up well with age while others show significant declines. Populations around the world are rapidly ageing. According to WHO, between 2000 and 2050, the fraction of the world's population over 60 years will double from about $11 \%$ to $22 \%$. The absolute number of people aged 60 years and over is expected to increase from 605 million to 2 billion over the same period [1]. In normal aging, decreased ability to retrieve information can cause annoying memory lapses that do not impair the ability to perform activities of daily living [2]. These changes are largely the result of declines in frontal lobe function, which is measured as executive function (the ability to organize, plan, and focus on a topic [3]. Age-related changes to the brain have been shown to occur earliest in the prefrontal cortex (PFC) [4]. The PFC has been associated with memory, attention, executive function and emotion, as well as playing a role in a variety of other complex cognitive functions [5]. Findings show that different components of executive function such as working memory, attention, and cognitive flexibility, are strongly impaired by aging [6]. Change in frontalstriatal circuits is the most likely significant cause of reduced executive function in non-demented older adults [7]. Numerous therapeutic options have been practiced for the management of cognitive impairment in the elderly such as oral medications cognitive interventions and diet etc, [8] the efficacy of such treatments can be limited and motivates a wide-ranging search for effective therapies. Relaxation Practices of yoga have shown various health benefits including the ability to improve Selective attention, concentration, visual scanning abilities, speed of information processing and a repetitive motor response[10]; thereby preventing cognitive impairments [9]. Multiple studies have shown that meditation practices have various health benefits including the possibility of preserving cognition and preventing dementia [12]. In the above context, the aim of this study was to test the effect of MSRT on cognitive functions of the elderly. 


\section{MATERIALS AND METHODS}

A total of 30 healthy elderly sample were recruited for the study using purposive sampling. The researcher approached all parks and health clubs in and around Banashankari area of Bangalore. The approval from Institutional Ethics Committee of Swami Vivekananda Yoga Anusandhana Samasthana (SVYASA) was obtained. All the elderly who were willing to participate and who fulfilled the inclusion and exclusion criteria were selected to participate in the study. The researcher followed this procedure of recruitment till a sample size of 30 was reached. Written informed consent was taken from all 30 subjects. A Single group pre-post design was used for the study. Subjects who were healthy, age between-6080 yrs, Education: $10^{\text {th }}$ std and above and those knowing Kannada, Hindi, English were included. Those having neurological and psychiatric disorders (based on case history), those who have practiced Yoga for the last 3 months and those who have major eyesight problems (in vision) were excluded from the study.

Assessments were conducted on Day 1 before intervention and after 30 days of MSRT intervention (on 30th day). The variables used in this study were:

- Attention and concentration (Six letter cancellation test)

- $\quad$ Executive functions (Trail making test B)

Six-letter cancellation test (SLCT) [13]: for adults is a paper-and pencil test that uses a letter cancellation task that measures cognitive functions such as selective and focused attention, concentration, visual scanning as well as activation and inhibition of rapid responses. For others, they are measures of efficiency and speed of visual scanning, or selective attention for yet others, they are administered primarily to assess potential hemispatial inattention and visual neglect, [14], or motor preservative behavior. However, they have also been utilized in neuropsychological test batteries for the assessment of the effectiveness of treatment for adult patients with anorexia nervosa and bulimia nervosa, and for the assessment of illiterate individuals to determine if education affected performance in a neuropsychological battery. They have also been employed to assess cognitive impairments in alcoholic cirrhotic patients, and to evaluate target detection deficits in patients who have undergone frontal lobectomy surgery. It consists of a test worksheet that specifies six target letters to be cancelled and has a 'working section', which consists of letters of the alphabet, arranged randomly in 22 rows and 14 columns. The participants are asked to cancel as many of the six target letters as possible in a specified time of 90 seconds. The total number of cancellations and wrong cancellations are scored, and the net scores are calculated by deducting wrong cancellations from the total attempt. This test has been evaluated for its reliability and validity based on standard criteria. Reliability has been ascertained based on (a) temporal stability and (b) internal consistency. The content validity of this test is adequate for the purpose for which it is intended. The normal value for healthy Indian adults for SLCT is $38 \pm 6$.

The Trail Making Test (TMT) [15]: is one of the most popular neuropsychological tests and is included in most test batteries. It is a measure of visual scanning, complex attention, psychomotor speed mental flexibility, and executive functions. The TMT is an adaptation of John E. Partington's Test of Distributed Attribution, which was originally developed in 1938 to assess intellectual function. It was later renamed Partington's Pathways Test and was used to examine the effects of opiate use on brain function. Subsequently it was incorporated into the Army Individual Test Battery where it received its current name. It was incorporated into the Halstead-Reitan Battery [16]. TMT-B requires an individual to draw lines sequentially connecting encircled numbers and letters distributed on a sheet of paper. The person must alternate between numbers and letters (e.g., 1, A, 2, B, 3, C, etc.). The score represents the amount of time required to complete the task. The TMT is sensitive to a variety of neurological impairments and TMT-B reflects primarily working memory and secondarily task-switching ability.

\section{Intervention}

The procedure used for MSRT session was adapted from the book 'mind sound resonance technique', Mind sound resonance technique (MSRT) is one of the advanced guided yoga relaxation techniques that can be practiced in supine or sitting posture for achieving the goal of positive health, will power, concentration and deep relaxation[17] This tool [Table 1] was developed using the concepts from traditional texts that talk about the power of Om (Mandukya Upanishad) and Nadanusandhana (HathaYoga Pradipika) for achieving internal mastery over the modifications of the mind (Patanjali's definition of yoga). MSRT opens up the secret of traditional chants called Mantras. 
Table-1: Steps of MSRT

\begin{tabular}{|l|l|}
\hline Practice & Duration \\
\hline Prayer - salutation to the divine (Maha Mrityunjaya Mantra) & 1 minute \\
\hline Quick relaxation technique - observe the abdominal breathing internally with closed eyes & 3 minutes \\
\hline Loud chanting (Ahata) of A, U, M and AUM (three rounds) & \\
\cline { 1 - 1 } $\begin{array}{l}\text { Alternate loud (Ahata) and mental (Anahata) chanting of A, U, M and AUM (three rounds) } \\
\text { Ahata of a long chant invoking fearlessness - Maha Mrityunjaya Mantra (three rounds) }\end{array}$ & \\
\hline Alternate Ahata-anahata of Mahamrityunjaya mantra (three rounds) & \\
\cline { 1 - 1 } Anahata of AUM (three rounds) & \\
\cline { 1 - 2 } Silence & \\
\hline Resolve &
\end{tabular}

\section{RESULTS}

A total of 40 subjects were screened for the study. Out of this sample, 10 subjects were excluded because a) declined to participate in the study $(n=5)$ or b) they did not meet the inclusion criteria $(n=5)$. The remaining 30 subjects were participated in the study 30 subjects completed the study, which was conducted at the end of one month; data was analyzed using IBM Statistical SPSS 21 package. The baseline values for Trail Making Test - Part B (TMT B) and six letter cancellation test (SLCT) for both groups are normally distributed $(\mathrm{p}>0.05)$. Based on the normality test values, parametric tests such as independent sample $\mathrm{t}$ test, was used to analyze TMT $-\mathrm{B}$ and SLCT test scores.

Trail making test $-B$

The baseline data were normally distributed. Paired sample -t test showed significant reduction $(\mathrm{P}<0.000)$ in time taken to complete the trail making test with respect to pre value. After one month of MSRT practice. Table and fig. show the details.

Table-2: Changes in TMT-B test scores after one month of MSRT

\begin{tabular}{|c|c|c|c|c|c|c|c|c|}
\hline \multirow{3}{*}{$\begin{array}{c}\text { Trail } \\
\text { making test- } \\
\text { B }\end{array}$} & \multicolumn{5}{|c|}{ Paired Differences } & \multirow[t]{3}{*}{$\mathbf{t}$} & \multirow[t]{3}{*}{ df } & \multirow[t]{3}{*}{ Sig. (2-tailed) } \\
\hline & \multirow[t]{2}{*}{ Mean } & \multirow[t]{2}{*}{$\begin{array}{c}\text { Std. } \\
\text { Deviation }\end{array}$} & \multirow[t]{2}{*}{$\begin{array}{l}\text { Std. Error } \\
\text { Mean }\end{array}$} & \multicolumn{2}{|c|}{$\begin{array}{c}95 \% \text { Confidence Interval of } \\
\text { the Difference }\end{array}$} & & & \\
\hline & & & & Lower & Upper & & & \\
\hline TM-Pre & 179.9 & 28.74 & \multirow{2}{*}{2.077} & \multirow{2}{*}{22.75} & \multirow{2}{*}{31.24} & \multirow[t]{2}{*}{12.995} & \multirow[t]{2}{*}{29} & \multirow[t]{2}{*}{$.000 * * *$} \\
\hline TM-Post & 152.9 & 26.04 & & & & & & \\
\hline
\end{tabular}

Legend: there is significant reduction in TMT-B scores $(\mathrm{P}<0.000 * * *)$.

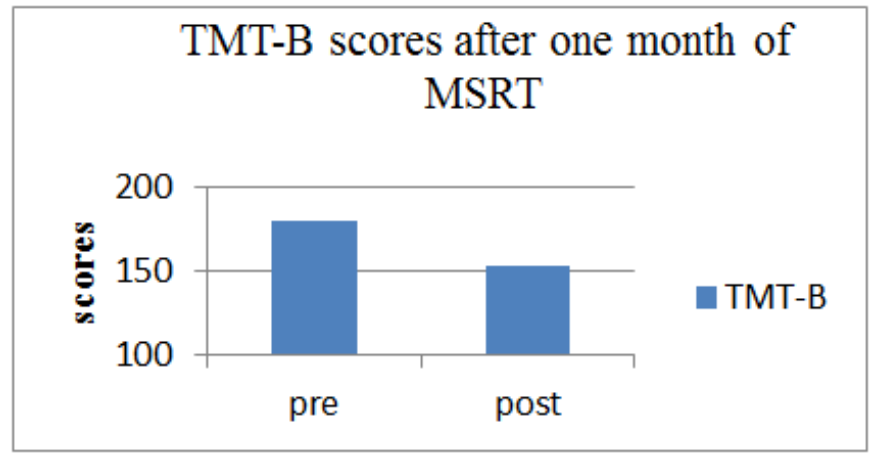

Graph-1: significant reduction in Trail making test-B scores after one month of MSRT practice

\section{Six letter cancellation test}

The baseline data were normally distributed.

Paired sample - $t$ test showed significant increase
$(\mathrm{P}<0.000)$ in net scores in six letter cancellation test with respect to pre value after one month of MSRT practice. Table and fig. show the details.

Table-3: Changes in SLCT test scores after one month of MSRT

\begin{tabular}{|c|c|c|c|c|c|c|c|c|}
\hline \multirow{3}{*}{$\begin{array}{c}\text { SIX LETTER } \\
\text { CANCELLATION } \\
\text { TEST }\end{array}$} & \multicolumn{5}{|c|}{ Paired Differences } & \multirow[t]{3}{*}{$\mathbf{t}$} & \multirow[t]{3}{*}{ df } & \multirow{3}{*}{$\begin{array}{l}\text { Sig. (2- } \\
\text { tailed) }\end{array}$} \\
\hline & \multirow[t]{2}{*}{ Mean } & \multirow[t]{2}{*}{$\begin{array}{c}\text { Std. } \\
\text { Deviation }\end{array}$} & \multirow{2}{*}{$\begin{array}{l}\text { Std. } \\
\text { Error } \\
\text { Mean }\end{array}$} & \multicolumn{2}{|c|}{$\begin{array}{l}\text { 95\% Confidence Interval } \\
\text { of the Difference }\end{array}$} & & & \\
\hline & & & & Lower & Upper & & & \\
\hline NET-Pre & 24.3 & 4.72 & \multirow[t]{2}{*}{.623} & \multirow[t]{2}{*}{-5.274} & \multirow[t]{2}{*}{-2.725} & - & \multirow[t]{2}{*}{29} & \multirow[t]{2}{*}{$.000 * * *$} \\
\hline NET-Post & 28.3 & 5.39 & & & & 6.41 & & \\
\hline
\end{tabular}

Legend: there is significant increase in net SLCT scores $(\mathrm{P}<0.000 * * *)$. 


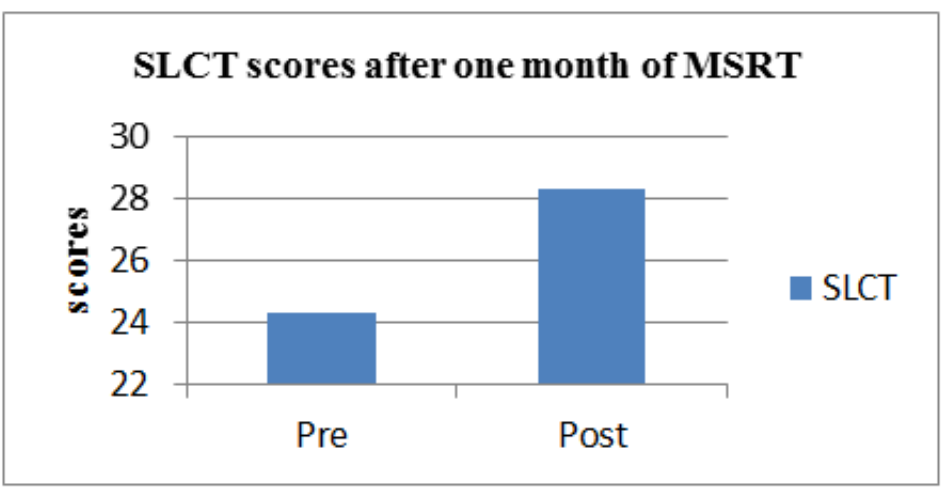

Graph-2: Significant increase in six latter cancelation test scores after one month of MSRT practice

\section{DISCUSSION}

The results of this study suggest that MSRT (Yogic relaxation technique) can be an effective non pharmacologic alternative for preserving and enhancing the cognitive functions among elders. Relaxation training is thought to improve one's ability to remain vigilant and monitor distractors without losing focus. The results provide evidence that while MSRT practice increases performance on tests of cognitive functions, in a study, P300 amplitude increased immediately after yogic relaxation technique [9]. Selective attention, concentration, visual scanning abilities, and a repetitive motor response have been seen to improve after Yoga based relaxation techniques [10]. In another study, attention, speed of information processing and motor speed increased after relaxation techniques [11]. Duel benefit of MSRT comes from the meditative effect along with its relaxation component. Relaxation may reduce stress-induced cortisol secretion and this could have neuroprotective effects potentially via elevating levels of brain derived neurotrophic factor (BDNF) also meditation processes are linked to GABAergic cortical inhibition, a mechanism implicated in improved cognitive performance and enhanced emotional regulation [18]. Meditation practices have various health benefits including the possibility of preserving cognition and preventing dementia [12]. Further, meditation may potentially strengthen neuronal circuits and enhance cognitive reserve capacity. Brain regions associated with attention, interception and sensory processing are thicker in meditation practitioners including the prefrontal cortex and right anterior insula. Advanced meditators have higher melatonin levels (that blocks the build-up of beta-amyloid plaque -a hallmark feature of Alzheimer's disease) than non-meditators [19]. Relaxation techniques have shown to reduce anxiety and improve memory as well as attention. It is already known that reduced anxiety [20] can improve the performance on tasks requiring attention and memory. So the improved performance could also be attributed to the reduced anxiety [21]. The study period was only of one month; still we could see significant improvement. Thus we can make a statement from our results that first time Yoga participants, if provided with just one month of MSRT intervention, can improve their executive and cognitive functioning. The study has limitations so that more studies are needed. Combined studies using EEG and fMRI with longer intervention duration and larger sample sizes would better define brain regions involved; also, a variety of tools could be used to assess cognitive functions.

\section{ACKNOWLEDGEMENT}

Conflict of interest: None

Financial aid: None

\section{CONCLUSION}

In summary, the data demonstrate that MSRT improves cognitive functions and shows the possibility of preserving cognition and preventing dementia. We conclude that MSRT can be provided to a group which is prone for cognitive decline and to those who have not been exposed to any cognition improving interventions; it can be helpful in improving their cognition.

\section{REFERENCES}

1. World Health Organization. (2013). Ageing and Life Course: Programmes and project. Available from: http://www.who.int/ageing/en/.

2. Squire, L.R. (1987). Memory and Brain, New York: Oxford U.P.

3. Schacter, D.L. (1997). Searching for Memory: The Brain, the Mind, and the Past, New York: Basic Books; 280-308.

4. Smith, E., Jonides, J. (1999). Storage and executive processes in the frontal lobes. Science, 283:16571661.

5. Gray, J.R., Braver, T.S., Raichle, M.E. (202). Integration of emotion and cognition in the lateral prefrontal cortex. Proc Natl Acad Sci, 99:41154120.

6. Kramer, A.F., Hahn, S., Cohen, N.J. (1999). Ageing, fitness and neurocognitive function. Nature, 400(6743):418-419.

7. Randy, L., Buckner. (2004). Memory and Executive Function Review in Aging and AD: Multiple Factors that Cause Decline and Reserve Factors that Compensate. Neuron, 44:195-208.

8. Talwadkar, S., Jagannathan, A., Raghuram, N. (2014). Effect of trataka on cognitive functions in the elderly. Int J Yoga, 7(2):96-103. 
9. Sarang, S.P., Telles, S. (2006). Changes in p300 following two yoga-based relaxation techniques. Int J Neurosci, 116(12):1419-30.

10. Sarang, S.P, Telles, S. (2007). Immediate effect of two yoga-based relaxation techniques on performance in a letter-cancellation task. Percept Mot Skills, 105(2):379-85.

11. Subramanya, P., Telles, S. (2009). Performance on psychomotor tasks following two yoga-based relaxation techniques. Percept Mot Skills, 109(2):563-76.

12. Xiong, G.L., Doraiswamy, P.M. (2009). Does Meditation Enhance Cognition and Brain Plasticity? Annals of the New York Academy of Sciences, 1172:63-69.

13. Diller, L., Ben, Y.Y., Gerstman, L.J., Goodin, R., Gordon, W., Weinberg, J. (1974). Studies in scanning behavior in hemiplegia. Rehabilitation Monograph No. 50, Studies in cognition and rehabilitation in hemiplegia. New York: New York University Medical Center, Institute of Rehabilitation Medicine.

14. Adair, J.C., Na, D.L., Schwarz, R.L., Heilman, K.M. (1998). Analysis of primary and secondary influences on spatial neglect. Brain Cogn, 37:35167.

15. Lezak, M.D. (1995). Neuropsychological Assessment 3rd ed, New York: Oxford U.P.

16. Reitan, R.M., Wolfson, D. (1985). The HalsteadReitan Neuropsycholgical Test Battery: Therapy and clinical interpretation. Tucson, AZ: Neuropsychological Press.

17. Nagendra, H.R. (2001). Mind sound resonance technique. Bangalore: Swami Vivekananda Yoga Prakashana.

18. Guglietti, C.L., Daskalakis, Z.J., Radhu, N., Fitzgerald, P.B., Ritvo, P. (2013). Meditationrelated increases in GABAB modulated cortical inhibition. Brain Stimul, 6(3):397-402.

19. Solberg, E.E., Holen, A., Ekeberg, O., Osterud, B., Halvorsen, R., Sandvik, L. (2004). The effects of long meditation on plasma melatonin and blood serotonin. Med Sci Monit, 10(3):CR96-101.

20. Jennifer, A.G., Herbert, B. (2006). The relaxation response: Reducing stress and improving cognition in healthy aging adults. Complementary Therapies in Clinical Practice, 3(12):186-191.

21. Saltz, E. (1970). Menifest anxiety: have we missed the data?. Psycho Rev, 77:568-573. 